\section{Your destiny, from day one}

\author{
The mammalian body \\ plan starts being laid \\ down from the
} moment of conception, it has emerged. Helen Pearson considers the implications of a surprising shift in
embryological thinking.

Y our world was shaped in the first 24 hours after conception. Where your head and feet would sprout, and which side would form your back and which your belly, were being defined in the minutes and hours after sperm and egg united.

Just five years ago, this statement would have been heresy. Mammalian embryos were thought to spend their first few days as a featureless orb of cells. Only later, at about the time of implantation into the wall of the uterus, were cells thought to acquire distinct 'fates' determining their positions in the future body.

But by tagging specific points on mammalian eggs shortly after fertilization, researchers have now shown that they come to lie at predictable points in the embryo. Rather than being a naive sphere, it seems that a newly fertilized egg has a defined top-bottom axis that sets up the equivalent axis in the future embryo. Controversially, one group even claims that the spot on the egg at which the sperm enters determines where the first cell division occurs - and that the resulting two cells already have a bias towards different fates.

This new understanding opens fresh avenues of study for developmental biologists. But it also raises the possibility that any technique that meddles with early human development - such as the removal of cells from an early embryo for pre-implantation genetic testing - might potentially be harmful. "It's possible you could be removing a cell with a predictable fate and causing damage," says Alan Handyside, who studies embryo abnormalities at the University of Leeds, UK.

Biologists have long known that the eventual axes of the embryo in most species are laid down either before fertilization, or in the first hours afterwards. In fruit flies, for

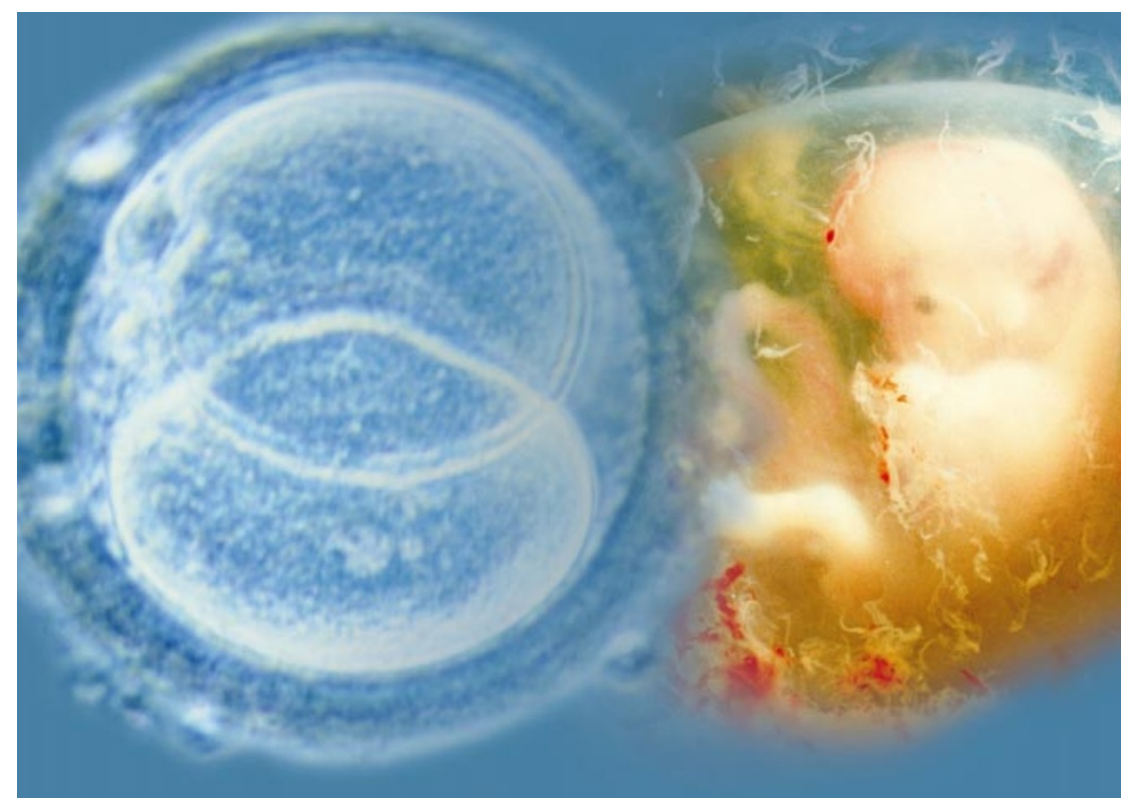

Axes established in the two-celled embryo (left in this montage) set up those in the fetus.

instance, the egg inherits a molecule that is more concentrated at one end of the egg than the other, and thus defines the head-tail axis.

\section{Heads or tails?}

But mammalian embryos were considered to be a special case. First, they have a striking ability to compensate for damage. Split up the first two cells of a mouse embryo and both recover to make two apparently normal mice. Second, only around $15 \%$ of cells in the blastocyst - a hollow sphere of cells that forms some five days after conception contribute towards the body proper, rather than supporting tissues such as the placenta. These cells reside in a structure called the inner cell mass (ICM). Finally, the first visible sign of a distinguishable head or tail takes 6.5 days to appear in mouse embryos. "All that argued against the idea of there being a map on the egg," says developmental biologist John Gurdon of the Wellcome/ Cancer Research UK Institute of Cancer and

This way up: Richard Gardner injected oil drops into two-celled embryos (below), giving markers that showed up in the blastocyst (below right).

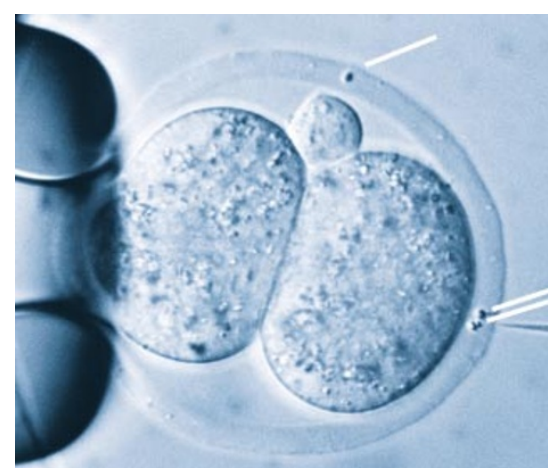

Developmental Biology in Cambridge.

The first hint that the blastocyst was not the unassuming orb it appeared came in the 1980s. Two little-noticed studies from Jean Smith of Queen's College in Flushing, New York, showed that the mouse blastocyst, rather than a being a symmetrical sphere, is slightly distorted and has recognizable axes $^{1,2}$. What's more, these axes appeared to match up with those of the fetus, suggesting that the former sets up the latter.

The findings prompted Richard Gardner, an embryologist at the University of Oxford, UK, to repeat the work, drawing similar conclusions ${ }^{3}$. But it took another five years before Gardner could make
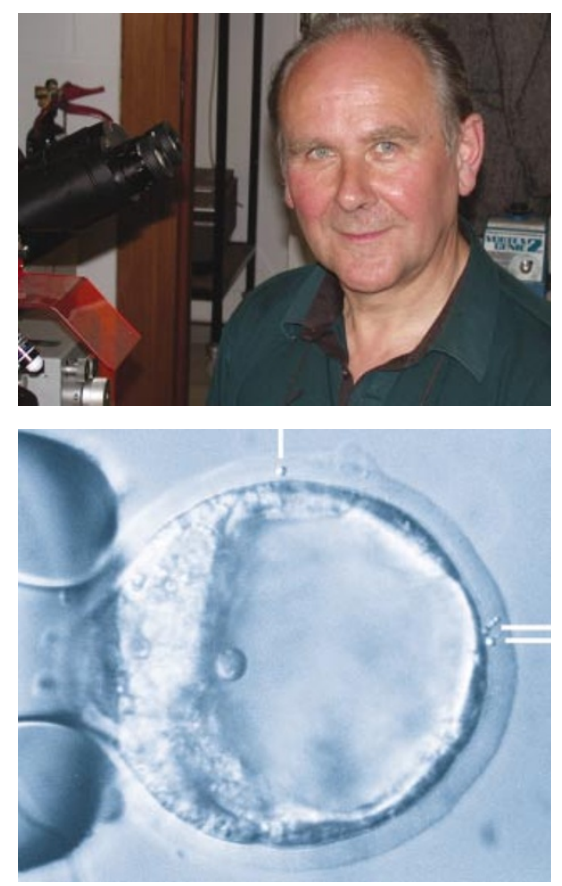

NATURE |VOL 418 4 JULY 2002 |www.nature.com/nature 
anyone listen. "People were quite hostile," he recalls.

Gardner suspected that the axes present in the blastocyst were there from the moment of conception. But to show that a specific point on the fertilized egg consistently maps to a particular position on the embryo, he needed a way of tagging the egg without disturbing it. He found such a marker in the form of the second polar body, a 'spare' set of chromosomes thrown out of the egg when the sperm enters: it remains glued to the embryo's surface in a set position.

\section{Impossible to ignore}

Examining blastocysts, Gardner found that the polar body consistently perched on a line of latitude dividing the upper hemisphere, containing the ICM, from the lower hemisphere ${ }^{4}$. This suggested that the top and bottom of the egg line up with, and may determine, the left and right sides of the blastocyst. He backed up this idea by using oil drops placed in the jelly-like protein coat of two-cell embryos to trace cell axes more accurately. "People could no longer ignore that there was patterning information in the egg," says Gardner.

Meanwhile, Magdalena Zernicka-Goetz's team at the Wellcome/Cancer Research UK Institute had found that this pattern is retained by the embryo after implantation. The researchers took unimplanted blastocysts and labelled cells at one or other pole of each with a fluorescent protein before transferring them into female mice and allowing them to implant. After 6.5 days, these cells ended up towards either one end or the other of the embryo ${ }^{6}$.

But how does the initial pattern get there? Zernicka-Goetz suspected the act of fertilization itself was the key, and injected sticky fluorescent beads under the coat of mouse eggs at the spot where sperm had penetrated. In most cases, the bead's position roughly coincided with the equator of the first cell division, implying that the sperm's entry point determines where the cell first divides ${ }^{7}$.

In subsequent experiments, ZernickaGoetz painted the first two cells, one red, one blue, using dyes dissolved in olive oil. She then tracked their descendants into the blastocyst. One cell usually gave rise to the region containing the ICM, the other to the region largely destined to make the placenta and other supporting tissues ${ }^{8}$.

Zernicka-Goetz's conclusion is that the first division of the egg influences the fate of each cell and ultimately, all the tissues of the body. "There is a memory of the first cleavage in our life," says Zernicka-Goetz.

Gardner disputes the idea that the sperm entry point is critical, arguing that ZernickaGoetz's fluorescent beads are drifting away from the point of fertilization. In recent work, he used components of the sperm's discarded tail to mark its entry position into
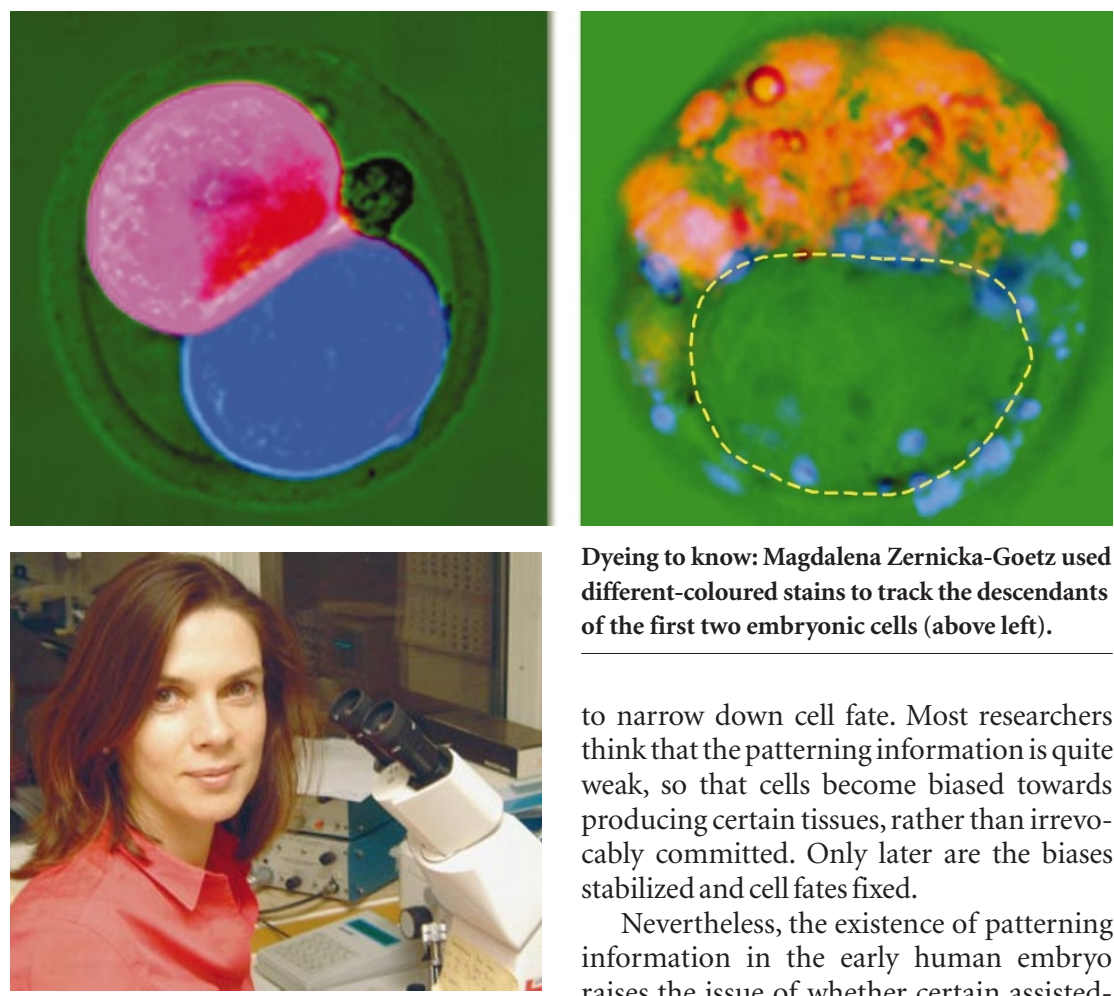

Dyeing to know: Magdalena Zernicka-Goetz used different-coloured stains to track the descendants of the first two embryonic cells (above left).

to narrow down cell fate. Most researchers think that the patterning information is quite weak, so that cells become biased towards producing certain tissues, rather than irrevocably committed. Only later are the biases stabilized and cell fates fixed.

Nevertheless, the existence of patterning information in the early human embryo raises the issue of whether certain assistedthe egg, and found no association with the equator of the first cell division ${ }^{9}$. ZernickaGoetz has countered with a third way of marking the entry site using fluorescently labelled sperm that transfer their label to the egg — and re-asserted her original conclusion $^{10}$. She is now working on eggs triggered into developing without sperm. If the first cell division in these embryos produces cells that contribute more equally to each half of the blastocyst, it will boost her theory that the point of sperm entry is the key factor.

\section{Patterns pending}

Developmental biologists are now keen to work out the molecular mechanisms underlying the patterning information in early mammalian embryos. As in fruit flies, they may contain an asymmetrically distributed 'determinant', a molecule that influences cell fate and is inherited unequally in the first cell division. Jonathan Van Blerkom of the University of Colorado at Boulder has intriguing evidence that two proteins are distributed in this way in human and mouse eggs ${ }^{11}$. He does not believe that these molecules are the determinants, but rather that their distribution is determined by the action of a yet-to-be-discovered mechanism.

Other researchers suspect that the sperm's entry on one side triggers a complete reorganization of the egg's internal skeleton that then makes cells at different positions in the embryo divide at slightly different times.

Another mystery is how early mammalian embryos retain the ability to develop normally if damaged or split in two, given the existence of patterning information that appears reproduction techniques could disrupt the delicate processes of establishing body axes.

If sperm entry point is an important factor, for instance, that throws up questions about intra-cytoplasmic sperm injection, in which sperm from infertile men are injected directly into the egg. Pre-implantation genetic testing, in which two cells are removed from an eight-cell embryo to test for inherited diseases such as cystic fibrosis, is another area of concern. "Perhaps we should pay attention to which cells we remove," says Handyside. But other experts believe that the flexibility of human embryos is sufficient to compensate for these manipulations. Damaged embryos may, in any case, spontaneously abort.

What is clear is that developmental bioloembryos as featureless bundles of cells and that leaves them with some work to do."I believe in the new philosophy," says Tom Fleming, a developmental biologist at the University of Southampton, UK, "but there's a lot of detail yet to be understood."

Helen Pearson works in Nature's news syndication team.

1. Smith, L. J. J. Embryol. Exp. Morph. 55, 257-277 (1980).

2. Smith, L. J. J. Embryol. Exp. Morph. 89, 15-35 (1985).

3. Gardner, R. L., Meredith, M. R. \& Altman, D. G.

J. Exp. Zool. 264, 437-443 (1992).

4. Gardner, R. L. Development 124, 289-301 (1997)

5. Gardner, R. L. Development 128, 839-847 (2001)

6. Weber, R. J., Pedersen, R. A., Wianny, F., Evans, M. J. \& Zernicka-Goetz, M. Development 126, 5591-5598 (1999).

7. Piotrowska, K. \& Zernicka-Goetz, M. Nature 409, 517-521 (2001)

8. Piotrowska, K. et al. Development 128, 3739-3748 (2001).

9. Davies, T. J. \& Gardner, R. L. Hum. Reprod. (in the press)

10. Plusa, P., Piotrowska, K. \& Zernicka-Goetz, M. Genesis 32, 193-198 (2002).

11. Antcsak, M. \& Van Blerkom, J. Mol. Hum. Reprod. 3, 1067-1086 (1997). gists will no longer dismiss early mammalian 